\title{
AIDS, Black
}

National Cancer Institute

\section{Source}

National Cancer Institute. AIDS, Black. NCI Thesaurus. Code C18622.

AIDS related research with a minimum of $20 \%$ (or $\$ 100,000)$ relevance to individuals of African descent 